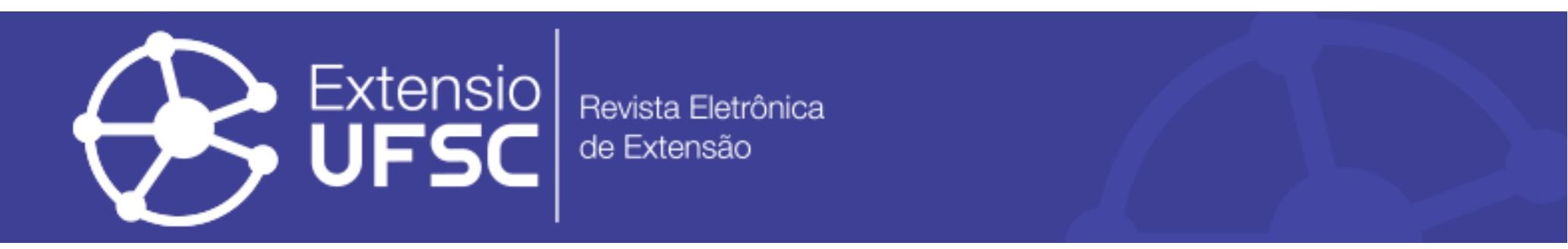

\title{
RESULTADOS DO PLANEJAMENTO ESTRATÉGICO SITUACIONAL EM UMA CENTRAL DE ABASTECIMENTO FARMACÊUTICO
}

\author{
Aisser Mota Mauad Jr \\ Universidade Federal de São João Del Rei \\ aissermauad@hotmail.com \\ Aline Resende Oliveira \\ Universidade Federal de São João Del Rei \\ cafdivinopolis@gmail.com
}

\author{
Thais Bueno Enes dos Santos \\ Secretaria de Saúde de Divinópolis \\ enesthais@gmail.com
}

André de Oliveira Baldoni Universidade Federal de São João Del Rei andrebaldoni@ufsj.edu.br

Cristina Sanches Giraud Universidade Federal de São João Del Rei csgiraud@ufsj.edu.br

\section{Resumo}

Historicamente, a união entre ensino e serviço mostra-se vantajosa para os dois setores envolvidos: o primeiro, por propiciar campo de atividade prática a seus discentes, e o segundo, por se beneficiar das inovações e discussões teóricas que enriquecem a prática. Adicionalmente, a incorporação de ferramentas de gestão da qualidade na assistência farmacêutica tem sido incentivada e fomentada no Sistema Único de Saúde por meio de programas que buscam a melhoria dos serviços ofertados aos usuários do sistema. Neste relato de experiência utilizou-se o Planejamento Estratégico Situacional (PES) proposto por Carlos Matus (1993) e adaptado por Leite et al (2016). Determinou-se como local/foco de atuação a Central de Abastecimento Farmacêutico (CAF) do município de Divinópolis, e como problema, as condições precárias de infraestrutura. As causas e consequências foram determinadas e analisadas conforme as quatro etapas do PES: explicativo, normativo, estratégico e tático-operacional. Durante a realização do trabalho, mudanças significativas ocorreram no serviço como relação direta, ou não, ao projeto. Entre as mudanças destacam-se: aquisição, pela instituição de ensino, de pallets de plástico para armazenamento adequado dos medicamentos, e a mudança da CAF para um local com melhores estrutura física e condições para o armazenamento de medicamentos. Resultados positivos foram obtidos por meio de parceria entre universidade e serviço, como a melhoria das condições técnicas de trabalho e de armazenamento dos medicamentos, beneficiando o usuário que irá receber medicamentos de qualidade, e o discente do curso de farmácia com um campo adequado para o desenvolvimento do seu estágio/prática.

Palavras-chave: Assistência Farmacêutica. Planejamento Estratégico Situacional. Sistema Único de Saúde.

\section{RESULTS OF SITUATIONAL STRATEGIC PLANNING IN A PHARMACEUTICAL SUPPLY CENTER}

\section{Abstract}

Historically, the union between teaching and service is advantageous for the two sectors involved, the first to provide a field of practical activity to its students and the second to benefit from the innovations and theoretical discussions that enrich the practice. In addition, the incorporation of quality management tools into pharmaceutical assistance has been encouraged and fostered in the Unified Health System through programs that seek to improve the services offered to the users of the system. In this report of experience we used the Strategic Situational Planning (PES) proposed by Carlos Matus (1993) and adapted by Leite et al (2016). The Pharmaceutical Supply Center (CAF) was defined as the location/focus of action, and the precarious infrastructure as a problem. The causes and consequences were determined and analyzed according to the four stages of ESP: explanatory, normative, strategic and tactical-operational. During the work, significant changes occurred in the service, and they were related or not with the project. Among the changes we had: acquisition by the teaching snstitution of plastic pallets for adequate storage of medicines, and the change from CAF to another place with better structure for the medicines storage. Positive results were obtained through a partnership between the university and the service, such as the improvement of the technical conditions of work and medicines storage, benefiting the users, that will receive medicines with quality; and the students of the pharmacy course with an adequatefield to develop your practice.

Keywords: Pharmaceutical Care. Situational Strategic Planning. Health Unic System. 


\section{RESULTADOS DEL PLANIFICACIÓN ESTRATÉGICA SITUACIONAL EN UNA CENTRAL DE ABASTECIMIENTO FARMACÉUTICO}

\section{Resumen}

Históricamente, la unión entre enseñanza y servicio se muestra ventajosa para los dos sectores involucrados: el primero, por propiciar campo de actividad práctica a sus estudiantes, y el segundo, por beneficiarse de las innovaciones y discusiones teóricas que enriquecen la práctica. Además, la incorporación de herramientas de Gestión de la Calidad en la evaluación farmacéutica ha sido incentivada y fomentada en el Sistema Único de Salud brasileño por medio de programas que buscan la mejora de los servicios ofrecidos a los usuarios del sistema. En este relato de experiencia se utilizó la Planificación Estratégica Situacional (PES). Se determinó como local / foco de actuación la Central de Abastecimiento Farmacéutico (CAF) del municipio de Divinópolis, y como problema, las condiciones precarias de infraestructura. Las causas y consecuencias fueron determinadas y analizadas conforme a las cuatro etapas del PES: explicativo, normativo, estratégico y táctico-operacional. Durante la realización del trabajo, cambios significativos ocurrieron en el servicio como relación directa o no, al proyecto, y entre los cambios se destacan: adquisición, por la Institución de Enseñanza, de pallets de material plástico para almacenamiento adecuado dosis medicamentos, y el cambio de la CAF a un lugar con mejor estructura física y condiciones adecuadas para el almacenamiento de medicamentos. Los resultados positivos fueron obtenidos a través de la asociación entre Universidad y servicio, como la mejora de las condiciones técnicas de trabajo y de almacenamiento de los medicamentos, beneficiando al usuario que recibirá medicamentos de calidad, y el estudiante del curso de farmacia con un campo adecuado para el desarrollo de su práctica / práctica.

Palabras clave: Asistencia Farmacéutica. Planificación Estratégica Situacional. Sistema Único de Salud. 
Resultados do planejamento estratégico situacional em uma central de abastecimento farmacêutico

\section{INTRODUÇÃO}

É reconhecida a importância dos medicamentos no controle, prevenção e na cura de doenças, por isso é essencial também considerar as condições que possam garantir a qualidade da gestão técnica da assistência farmacêutica prestada, de modo a propiciar o fornecimento de medicamentos de qualidade. A assistência farmacêutica compreende os processos de seleção, programação, aquisição, armazenamento, distribuição e dispensação de medicamentos (Oliveira; Assis; Barboni, 2010; Correr; Otuki; Soler, 2011).

Entre os processos da assistência farmacêutica, o de armazenamento dos medicamentos visa a manutenção da qualidade e efetividade deste para a futura utilização no tratamento do paciente. Desta forma, os processos envolvidos na etapa de armazenamento devem ser feitos por pessoal capacitado para o seu desempenho, englobando desde o recebimento até a distribuição. Deverão ser utilizados conhecimentos técnicos e administrativos, evitando, por exemplo, a incidência de luz direta, ou temperatura e umidade acima dos padrões estabelecidos para a manutenção da estabilidade físico-química e microbiológica de cada medicamento (Brasil, 2006). Adicionalmente, devem ser implantadas ferramentas que visem otimizar o espaço destinado ao armazenamento e a metodologia de trabalho.

O Planejamento Estratégico Situacional (PES) (Matus, 1993) apresenta a vantagem de potencialização do alcance dos objetivos a serem cumpridos, elucidando os pontos a serem trabalhados, além de propor um planejamento participativo, sendo um modelo administrativo que vem sendo disseminado pelo território brasileiro e utilizado como modelo gestão de projetos na assistência farmacêutica.

\subsection{PROBLEMATIZAÇÃO}

A Central de Abastecimento Farmacêutico (CAF) do município de Divinópolis/MG recebe os estudantes do curso de Farmácia da Universidade Federal de São João Del-Rei (UFSJ), desde 2008, para os estágios supervisionados. Desta forma, este projeto surgiu a partir da demanda gerada pelos discentes do curso de Farmácia, após estágio na CAF e discussão em sala de aula. Visto a necessidade de mudança de diversas não conformidades encontradas no campo do estágio, o presente trabalho objetivou avaliar o impacto da implantação de um Planejamento Estratégico Situacional através de indicadores proporcionados pelo estudo de Leite et all, buscando promover melhorias na estrutura e rotina de trabalho da CAF. 
Resultados do planejamento estratégico situacional em uma central de abastecimento farmacêutico

\section{METODOLOGIA}

\subsection{DELINEAMENTO}

O presente estudo é um relato de experiência concebido como um projeto de extensão da Universidade Federal de São João Del-Rei (UFSJ), e realizado na CAF durante um período de 18 meses.

\subsection{LOCAL DO ESTUDO}

O trabalho foi desenvolvido na CAF do município dede Divinópolis/MG. A CAF é responsável pela distribuição de medicamentos para oito farmácias, onze postos de saúde, trinta e uma unidades estratégia saúde da família (ESF).

Em caso de surtos de doenças como no caso da H1N1, mais conhecida como gripe suína, a CAF também faz a distribuição para hospitais do setor privado.

No período do estudo, a CAF era estabelecida nas antigas instalações de um hospital psiquiátrico, de forma adaptada, desta forma, utilizavam-se os leitos do então hospital, como prateleiras para o armazenamento dos medicamentos. Em 30 de julho de 2009 foi realizada a última inspeção da vigilância sanitária, onde várias não conformidades foram apontadas, a maioria dessas em função de avarias no prédio devido ao curso do tempo, uma vez que o antigo hospital existia há mais de 16 anos.

\subsection{PROPOSTA DE INTERVENÇÃO}

A ferramenta utilizada no estudo foi o Planejamento Estratégico Situacional (PES) de Carlos Matus (1993) e adaptado por Leite (2016), o qual é dividido em quatro etapas bem delineadas.

A primeira etapa, denominada momento explicativo, foi o momento em que se analisou os principais problemas existentes na CAF e o espaço existente entre a resolução dos mesmos, identificando e selecionando os problemas mais urgentes a serem solucionados. Ao final do estudo, foram delimitados os descritores e distinguidas as causas e consequências relacionadas a estes descritores. Foram realizadas visitas ao local para análise do cenário, além de ser observada 
Resultados do planejamento estratégico situacional em uma central de abastecimento farmacêutico

a rotina de funcionamento da CAF, sendo selecionados quatro descritores principais:potencial alteração da estabilidade dos medicamentos, falta de condições de trabalho, ausência de fluxo de distribuição dos medicamentos e não regularização junto a ANVISA (Agência Nacional de Vigilância Sanitária) e CRF (Conselho Regional de Farmácia).

$\mathrm{Na}$ segunda etapa, ou momento normativo, são definidas operações e ações que podem ser realizadas, para que, em diferentes perspectivas, possa propor uma mudança na atual situação a levando em uma situação ideal. Neste momento, para melhor elucidação das causas e consequências a serem trabalhadas em cima dos descritores escolhidos, elabora-se uma rede explicativa destes, em nosso caso, no formato de um diagrama de causa e efeito (figura 3), considerado uma representação gráfica em forma de espinha de peixe que aponta do problema para a resolução do mesmo. Neste momento foram feitas discussões e anotações para identificar as individualidades de cada oportunidade de melhoria, evidenciando os recursos ou atores que podem atuar para solucionar o problema em questão e ajudar a se chegar a situação ideal.

$\mathrm{Na}$ terceira etapa, ou momento estratégico, analisaram-se os caminhos a serem seguidos através das operações e ações definidas no momento anterior, levando em consideração viabilidade e factibilidade das mesmas, elencando atividades estratégicas a serem seguidas no momento seguinte e identificando nós críticos existentes.

Por último, na quarta etapa, realizou-se o momento tático-operacional, considerada a etapa da ação, em que todo o estudo desenvolvido começa a se tornar realidade através ações concretas, sempre monitorando para que se possa fazer alguma alteração quando necessária e obedecendo os prazos estipulados nesta etapa. Em todas as quatro etapas foram utilizadas tabelas desenvolvidas pelo estudo de Leite et al (2016).

\section{RESULTADOS E DISCUSSÃO}

O trabalho teve início com um debate entre o professor responsável pelo estágio do curso de Farmácia e a Gerência da Assistência Farmacêutica da Secretaria Municipal de Saúde de Divinópolis/MG, evidenciando os primeiros problemas levantados pelos estudantes. Foram marcadas visitas a CAF para fazer avaliação diagnóstica do local.

Neste momento o PES começa a ser formado, sendo esta primeira etapa denominada de momento explicativo. Nesta etapa de ação, todos os problemas serão elencados e divididos por subgrupos e posteriormente é dada uma nota de 0 a 4 para cada um dos mesmos, sendo que 0 
Resultados do planejamento estratégico situacional em uma central de abastecimento farmacêutico

tem uma importância menor ou nula comparada a uma nota 4, considerada de grande importância. Os subgrupos existentes são: magnitude (número de pessoas ou frequência das mesmas que serão atingidas pelo problema), transcendência (grau de interesse da comunidade em resolver o problema), vulnerabilidade (grau de fragilidade em se realizar a intervenção com os materiais disponíveis), urgência (diretamente relacionado ao prazo e riscos envolvidos para resolução do problema) e factibilidade (disponibilidade de recursos e materiais necessários para resolver o problema). Seguindo o conceito de momento explicativo, foi realizada uma visita a CAF para saber das reais condições estruturais e problemas enfrentados (Leite, 2016).

$\mathrm{Na}$ chegada ao local, verificou-se que a CAF possuía um portão com interfone, restringindo o acesso de pessoas, já que havia certo movimento, por ser localizada ao lado do SERSAM (Serviço de Referência em Saúde Mental). No espaço interno da CAF, no local destinado à recepção e inspeção dos medicamentos, observaram-se inúmeras caixas de medicamentos, dispostas em pallets de madeira,sobre as quais incidia luz em grande quantidade, podendo alterar a estabilidade físico-química dos mesmos. O espaço, descumpria a RDC $\mathrm{n}^{\circ} 50$, de 21 de fevereiro de 2002, que evidencia a necessidade de 10\% do espaço físico da CAF deve ser destinada à recepção e inspeção de medicamentos (BRASIL, 2002).

$\mathrm{Na}$ entrada no edifício 1, que abrigava os medicamentos gerais, foi constatado a presença de armário para funcionários na parte interna, e também que as salas estavam sinalizadas e organizadas alfabeticamente. No final do corredor encontravam-se medicamentos vencidos que deveriam ser recolhidos para disposição final. A CAF não possuía um PGRSS (Programa de Gerenciamento de Resíduos de Serviços de Saúde), e os medicamentos ficavam armazenados no corredor indefinidamente (BRASIL, 2004).

As salas por sua vez, tinham piso formado por tacos de madeira, que se soltavam frequentemente e proporcionavam maior formação de pó, e inúmeros pallets de madeira, fazendo destes um ambiente susceptível à presença de insetos como cupins. Na parede das salas se encontravam o termohigrômetro e, ao lado, a folha onde se registrava o controle da temperatura e umidade da sala. Algumas salas possuíam ventiladores e nem todas tinham portas. As janelas não possuíam insulfilme para redução da luminosidade, desta forma, os funcionários tentavam improvisar a redução da incidência de luz na sala encaixando papelão remanescente das caixas que traziam os medicamentos (Fig.1). Em algumas salas não havia sequer o papelão, ocasionando a incidência de luz direta e constante nos medicamentos, fazendo com que fatores extrínsecos possam mudar, de forma parcial ou total, a estabilidade dos medicamentos armazenados, agilizando a velocidade das reações químicas (MARIN, 2003). 
Resultados do planejamento estratégico situacional em uma central de abastecimento farmacêutico

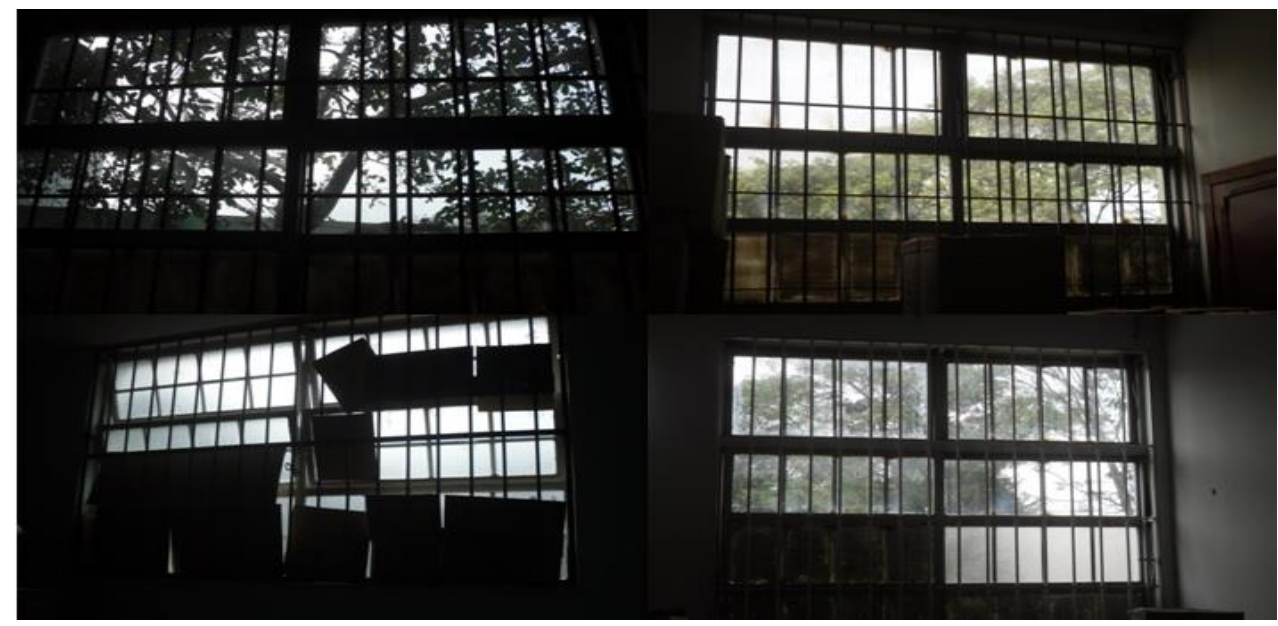

Figura 1 - Janelas de algumas salas da Central de Abastecimento Farmacêutico.

Levando-se em consideração também que, como a CAF era um antigo hospital psiquiátrico, haviam inúmeros sanitários desativados dentro das salas, com contato direto com as salas de armazenamento, diferente do indicado em literatura, em que o ambiente deveria ser construído propriamente com fim de armazenamento dos medicamentos. (MARIN, 2003).

A CAF também se localizava ao lado da Secretaria de Estado de Transporte, que por sua vez, jogava equipamentos e mobiliários inutilizados próximo a copa da CAF, fazendo com que ocorresse aumento da proliferação de baratas e ratos. Entre o lixo, estavam pallets de madeira usados, carrinhos de mão estragados, armários e diversos outros artigos de metal empoeirados, evidenciando que estavam ali já há algum tempo (Figura 2).

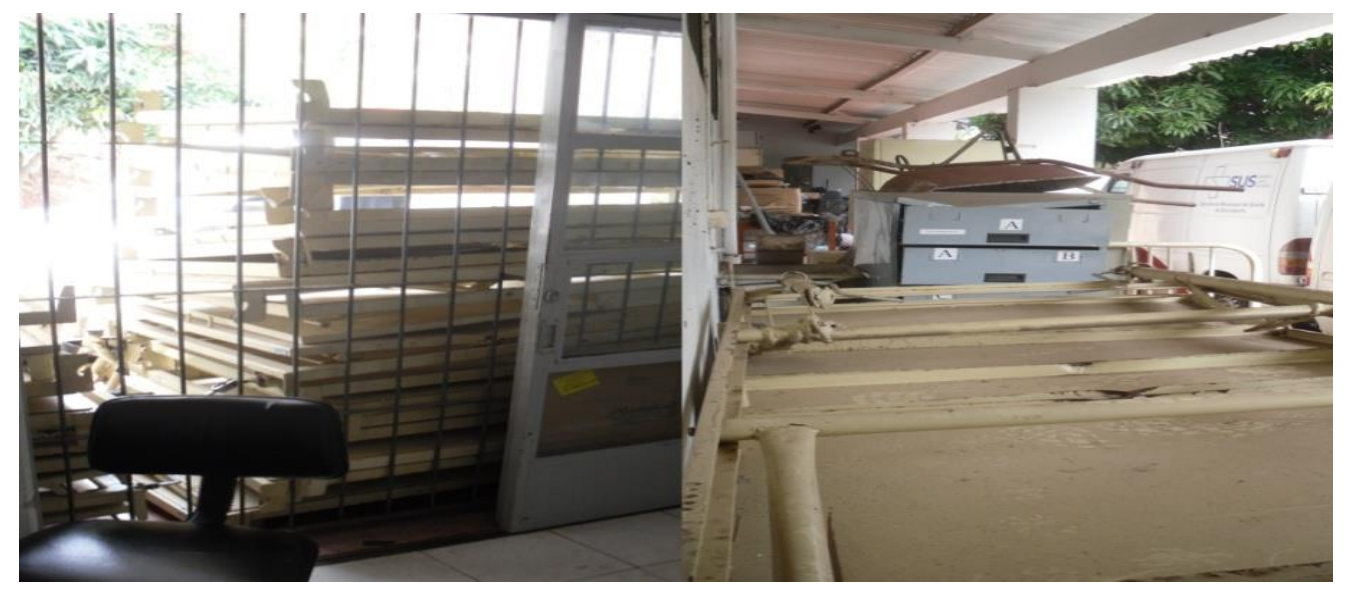

Figura 2 - Parte interna e externa da Central de Abastecimento Farmacêutico, evidenciando o lixo depositado. 
Resultados do planejamento estratégico situacional em uma central de abastecimento farmacêutico

Ao sair do edifício 1, em direção ao edifício 2, percebeu-se que uma das salas do primeiro não estava totalmente lacrada com grades, sendo possível algum invasor ter acesso a todos os medicamentos do edifício 1.

Ao entrar no edifício 2, onde ficavam armazenados os medicamentos termolábeis e controlados, observou-se que as geladeiras eram antiquadas, de uso doméstico e não próprias para armazenamento, não havendo sistema de descongelamento automático. As salas deste edifício também apresentavam os mesmos problemas do piso e das janelas do edifício 1, e a sala de medicamentos controlados estava trancada e não tivemos acesso. Ao abrir a porta de um dos banheiros desativados de uma das salas, um grande número de mosquitos apareceu, podendo ter ali, acúmulo de água parada.

Além disso, por meio de conversa com três funcionários que ali trabalhavam, foi constatado que não havia faxineira no local e os próprios funcionários tinham que deixar suas atividades técnicas de lado para fazer a limpeza da CAF. Os banheiros não continham lixeiras, sendo estas improvisadas utilizando-se caixas de medicamentos que sobravam.

Ao terminar de recolher todas as informações necessárias, foi-se então usado o método do planejamento estratégico situacional fundamentado por Carlos Matus, considerado por muitos um dos maiores do mundo sobre planejamento estratégico e capacidade de governo, e adaptado por Leite et al (2016), adentrando-se no momento explicativo e a priorização de problemas segundo tabela 01 .

Tabela 1 - Matriz de priorização de problemas relacionados no instrumento de reconhecimento e análise do território, conforme momento explicativo.

\begin{tabular}{|c|c|c|c|c|c|c|}
\hline \multirow[b]{2}{*}{ Problemas } & \multirow{2}{*}{\begin{tabular}{|l|} 
Magnitude \\
(Tamanho)
\end{tabular}} & \multirow{2}{*}{\begin{tabular}{c|} 
Transcendência \\
(Interesse)
\end{tabular}} & \multirow{2}{*}{$\begin{array}{c}\text { Vulnerabilidade } \\
\text { (Reversão) }\end{array}$} & \multirow{2}{*}{$\begin{array}{l}\text { Urgência } \\
\text { (Espera) }\end{array}$} & \multirow{2}{*}{$\begin{array}{c}\text { Factibilidade } \\
\text { Recursos) }\end{array}$} & \multirow[b]{2}{*}{ Total } \\
\hline & & & & & & \\
\hline $\begin{array}{l}\text { 1. Extintores inseridos de forma } \\
\text { inadequada. }\end{array}$ & 2 & 2 & 2 & 3 & 2 & 11 \\
\hline $\begin{array}{l}\text { 2. Pallets de madeira com } \\
\text { incidência de carunchos }\end{array}$ & 3 & 2 & 2 & 3 & 2 & 12 \\
\hline $\begin{array}{l}\text { 3. Falta de Plano de } \\
\text { Gerenciamento de Resíduos } \\
\text { dos Serviços da Saúde (PGRSS) }\end{array}$ & 2 & 2 & 2 & 4 & 2 & 12 \\
\hline $\begin{array}{l}\text { 4. Janelas mal cobertas, com } \\
\text { incidência de luz nos }\end{array}$ & 3 & 2 & 3 & 4 & 1 & 14 \\
\hline
\end{tabular}


Resultados do planejamento estratégico situacional em uma central de abastecimento farmacêutico

\begin{tabular}{|c|c|c|c|c|c|c|c|}
\hline & medicamentos. & & & & & & \\
\hline 5. & $\begin{array}{l}\text { Falta de separação de fluxos de } \\
\text { entrada e saída dos } \\
\text { medicamentos. }\end{array}$ & 3 & 2 & 1 & 4 & 1 & 11 \\
\hline 6. & $\begin{array}{l}\text { Salas faltando portas e outras } \\
\text { faltando ventilador, } \\
\text { dificultando controle da } \\
\text { temperatura. }\end{array}$ & 2 & 2 & 2 & 4 & 1 & 11 \\
\hline 7. & Falta de apoio institucional. & 3 & 2 & 3 & 4 & 3 & 15 \\
\hline 8. & $\begin{array}{l}\text { Fiação exposta em diversas } \\
\text { salas. }\end{array}$ & 3 & 2 & 3 & 3 & 2 & 13 \\
\hline 9. & $\begin{array}{l}\text { Abertura em uma das salas, } \\
\text { sem grades, que pode permitir } \\
\text { entrada de invasores }\end{array}$ & 4 & 2 & 2 & 4 & 1 & 13 \\
\hline 10. & $\begin{array}{l}\text { Excesso de lixo na área externa, } \\
\text { próximo a Copa, onde } \\
\text { funcionários se alimentam. }\end{array}$ & 4 & 2 & 3 & 4 & 2 & 15 \\
\hline
\end{tabular}

Posteriormente, com as notas já definidas, foram elucidados os descritores a serem trabalhados, definidos como a falta de apoio constitucional com 15 pontos, excesso de lixo na área externa, também com 15 pontos e, por fim, janelas mal cobertas com 14 pontos.

Após a visita e determinação dos problemas, foi então preparado o diagrama de causa e efeito, conhecido como diagrama espinha de peixe. De acordo com Matus (1993) é uma situação desejada a se chegar, que marca o posicionamento das estratégias a serem implantadas. Essa situação ideal ficou definida por armazenamento adequado de medicamentos na CAF.

Desta forma, partiu-se da situação atual, nomeada como "armazenamento inadequado de medicamentos na CAF", e com todos os seus descritores, sendo a causa principal a "falta de apoio institucional" e como principal consequência o "aumento de gastos públicos e o descontentamento do usuário do medicamento" (Figura 3). 
Resultados do planejamento estratégico situacional em uma central de abastecimento farmacêutico

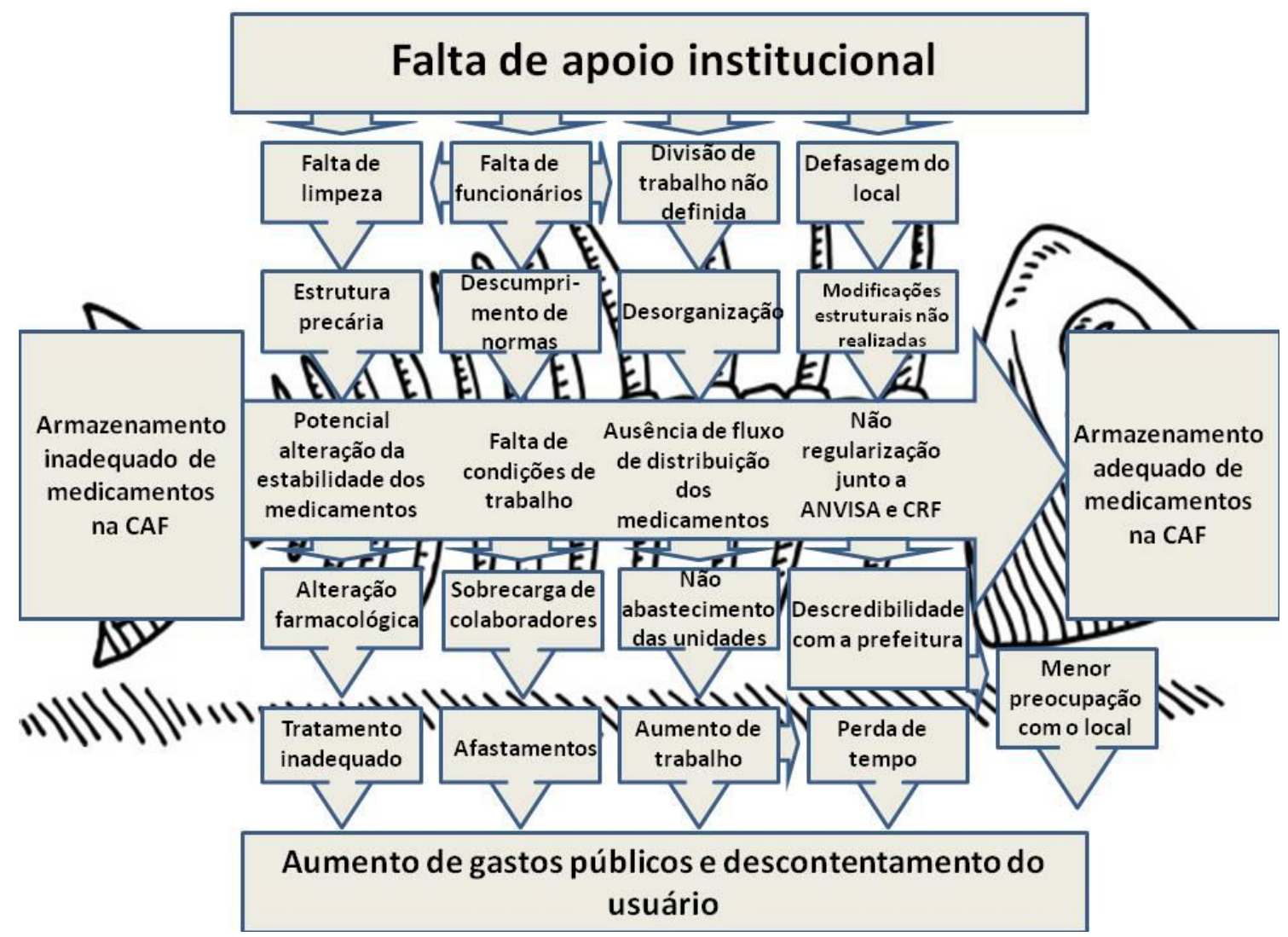

Figura 3 - Diagrama de Causa e Efeito. ANVISA: Agência Nacional de Vigilância Sanitária; CAF: Central de Abastecimento Farmacêutico; CRF: Conselho Regional de Farmácia;

Definidos os principais problemas relacionados a CAF, partiu-se para o segundo momento denominado normativo. Nesta etapa é desenhado um plano de ação relacionando cada operação e ação a um objetivo específico, conforme elucida tabela 02.

Tabela 02 - Objetivos específicos a serem trabalhados, juntamente com suas operações e ações a serem tomadas, conforme momento normativo.

\begin{tabular}{|c|c|c|}
\hline $\begin{array}{c}\text { OBJETIVOS } \\
\text { ESPECÍFICOS }\end{array}$ & OPERAÇÕES & AÇÕES \\
\hline \multirow{2}{*}{$\begin{array}{c}\text { Melhorar a infraestrutura } \\
\text { da Central de } \\
\text { Abastecimento }\end{array}$} & $\begin{array}{c}\text { Troca dos pallets de madeira por } \\
\text { pallets de plástico }\end{array}$ & $\begin{array}{c}\text { Buscar investimento com a } \\
\text { Prefeitura. }\end{array}$ \\
\cline { 2 - 3 } Farmacêutico & Compra de ventiladores para as salas \\
que não possuem & $\begin{array}{c}\text { Obtenção de orçamentos de } \\
\text { Universidade. }\end{array}$ \\
\cline { 2 - 3 } & Dispor os extintores de forma & compra para enviar á prefeitura. \\
\cline { 2 - 3 } & & Acessar as regulamentações e confecção de ofício de \\
\hline
\end{tabular}


Resultados do planejamento estratégico situacional em uma central de abastecimento farmacêutico

\begin{tabular}{|c|c|c|}
\hline OBJETIVOS & OPERAÇÕES & AÇÕES \\
\hline & regularizada & $\begin{array}{l}\text { propostas para disposição dos } \\
\text { extintores. }\end{array}$ \\
\hline & $\begin{array}{c}\text { Enegrecer janelas das salas de } \\
\text { armazenamento com tinta própria, e } \\
\text { paredes que contem presença de } \\
\text { mofo. }\end{array}$ & $\begin{array}{l}\text { Mutirão com os alunos da } \\
\text { Universidade. }\end{array}$ \\
\hline & $\begin{array}{c}\text { Fechamento da abertura que permite } \\
\text { a possível entrada de invasores. }\end{array}$ & $\begin{array}{l}\text { Diálogo com a Prefeitura para ceder } \\
\text { materiais e mão de obra. }\end{array}$ \\
\hline & & $\begin{array}{l}\text { Diálogo com a Universidade para } \\
\text { ceder materiais e mão de obra. }\end{array}$ \\
\hline & $\begin{array}{c}\text { Troca das geladeiras de uso } \\
\text { doméstico, para próprias de } \\
\text { armazenamento }\end{array}$ & $\begin{array}{l}\text { Orçamento e apresentação junto a } \\
\text { Prefeitura ou Universidade. }\end{array}$ \\
\hline \multirow{5}{*}{$\begin{array}{c}\text { Melhorar a qualidade de } \\
\text { trabalho na Central de } \\
\text { Abastecimento } \\
\text { Farmacêutico }\end{array}$} & \multirow[t]{2}{*}{$\begin{array}{l}\text { Retirar os lixos depositados na área } \\
\text { externa, próxima a Copa. }\end{array}$} & $\begin{array}{l}\text { Conversar com os órgãos públicos } \\
\text { localizados próximo a CAF para } \\
\text { retirada dos objetos. }\end{array}$ \\
\hline & & $\begin{array}{c}\text { Organizar mutirão para retirada dos } \\
\text { objetos. }\end{array}$ \\
\hline & $\begin{array}{l}\text { Troca das lixeiras de papelão por } \\
\text { lixeiras de plástico com pedal. }\end{array}$ & Compra de lixeiras novas. \\
\hline & $\begin{array}{l}\text { Contratação de um funcionário para } \\
\text { ficar responsável pela limpeza }\end{array}$ & $\begin{array}{l}\text { Buscar um funcionário capacitado e } \\
\text { disponível para o serviço e dialogar } \\
\text { com a Prefeitura para a contratação } \\
\text { do mesmo. }\end{array}$ \\
\hline & Evitar acúmulo de água parada & $\begin{array}{l}\text { Orientar os funcionários a ficarem } \\
\text { atentos a possíveis focos de Dengue. }\end{array}$ \\
\hline
\end{tabular}

No terceiro momento, o estratégico, começa-se a trabalhar com dois indicadores importantes: viabilidade e factibilidade. O primeiro relaciona-se ao grau de apoio e comprometimento pelos atores ou grupos socais no enfrentamento do determinado problema, enquanto o segundo segue na linha da existência ou não de recursos financeiros para resolução dos problemas. O momento estratégico é definido e proposto segundo tabela 03 . 


\section{Resultados do planejamento estratégico situacional em uma central de abastecimento farmacêutico}

Tabela 03 - No terceiro momento, o estratégico, foi feita a análise da viabilidade e factibilidade de cada operação proposta.

\begin{tabular}{|c|c|c|c|c|c|c|c|c|}
\hline $\begin{array}{l}\text { Objetivo } \\
\text { Específico }\end{array}$ & \multirow[b]{3}{*}{ Ações } & \multicolumn{7}{|c|}{ Melhorar a infraestrutura da Central de Abastecimento Farmacêutico } \\
\hline \multirow[b]{2}{*}{ Operações } & & \multicolumn{3}{|c|}{$\begin{array}{l}\text { ANÁLISE DE } \\
\text { VIABILIDADE }\end{array}$} & \multicolumn{2}{|c|}{$\begin{array}{c}\text { ANÁLISE DE } \\
\text { FACTIBILIDADE }\end{array}$} & \multirow[b]{2}{*}{ Déficit } & \multirow[b]{2}{*}{$\begin{array}{l}\text { Atividade } \\
\text { estratégica }\end{array}$} \\
\hline & & $\begin{array}{l}\text { deci- } \\
\text { dir }\end{array}$ & $\begin{array}{l}\text { execu } \\
\text {-tar }\end{array}$ & $\begin{array}{c}\text { man- } \\
\text { ter }\end{array}$ & $\begin{array}{l}\text { Recur- } \\
\text { sos } \\
\text { existen- } \\
\text { tes } \\
\end{array}$ & $\begin{array}{c}\text { Recursos } \\
\text { necessários }\end{array}$ & & \\
\hline \multirow{2}{*}{$\begin{array}{l}\text { Troca dos } \\
\text { pallets de } \\
\text { madeira por } \\
\text { pallets de } \\
\text { plástico }\end{array}$} & $\begin{array}{l}\text { Buscar } \\
\text { investimen- } \\
\text { to com a } \\
\text { Prefeitura. }\end{array}$ & Sim & $\operatorname{Sim}$ & $\operatorname{Sim}$ & Nenhum & $\begin{array}{l}\text { Recurso } \\
\text { financeiro }\end{array}$ & $\begin{array}{l}\text { Recurso } \\
\text { financeiro }\end{array}$ & $\begin{array}{l}\text { Reunião com } \\
\text { Secretário de } \\
\text { Saúde }\end{array}$ \\
\hline & $\begin{array}{l}\text { Buscar } \\
\text { investimento } \\
\text { com a } \\
\text { Universidade. }\end{array}$ & Não & Não & Não & Nenhum & $\begin{array}{l}\text { Recurso } \\
\text { financeiro }\end{array}$ & $\begin{array}{l}\text { Recurso } \\
\text { financeiro }\end{array}$ & $\begin{array}{l}\text { Reunião com } \\
\text { Diretor do } \\
\text { Campus }\end{array}$ \\
\hline $\begin{array}{c}\text { Compra de } \\
\text { ventiladores } \\
\text { para as salas } \\
\text { que não } \\
\text { possuem }\end{array}$ & $\begin{array}{c}\text { Obtenção de } \\
\text { orçamentos } \\
\text { de } \\
\text { ventiladores e } \\
\text { confecção de } \\
\text { ofício de } \\
\text { compra para } \\
\text { enviar á } \\
\text { prefeitura. }\end{array}$ & Sim & Sim & Não & $\begin{array}{l}\text { Computa- } \\
\text { dor e } \\
\text { telefone } \\
\text { para } \\
\text { pesquisa } \\
\text { de preços }\end{array}$ & $\begin{array}{l}\text { Computa- } \\
\text { dor e } \\
\text { telefone } \\
\text { para } \\
\text { pesquisa de } \\
\text { preços / } \\
\text { Recurso } \\
\text { financeiro }\end{array}$ & $\begin{array}{l}\text { Recurso } \\
\text { financeiro }\end{array}$ & $\begin{array}{l}\text { Apresentar o } \\
\text { ofício ao } \\
\text { Secretário de } \\
\text { Saúde e } \\
\text { explicar a } \\
\text { importância da } \\
\text { compra }\end{array}$ \\
\hline $\begin{array}{l}\text { Dispor os } \\
\text { extintores de } \\
\text { forma } \\
\text { regularizada }\end{array}$ & $\begin{array}{c}\text { Acessar as } \\
\text { regulamenta- } \\
\text { ções } \\
\text { propostas } \\
\text { para } \\
\text { disposição } \\
\text { dos } \\
\text { extintores. }\end{array}$ & Sim & Não & Não & $\begin{array}{l}\text { Mão de } \\
\text { obra }\end{array}$ & $\begin{array}{l}\text { Mão de } \\
\text { obra / } \\
\text { Recurso } \\
\text { financeiro }\end{array}$ & $\begin{array}{l}\text { Recurso } \\
\text { financeiro }\end{array}$ & $\begin{array}{l}\text { Sensibilizar o } \\
\text { Secretário de } \\
\text { Saúde do } \\
\text { perigo da não } \\
\text { disposição } \\
\text { correta dos } \\
\text { extintores. }\end{array}$ \\
\hline $\begin{array}{l}\text { Enegrecer } \\
\text { janelas das } \\
\text { salas de } \\
\text { armazena- } \\
\text { mento com } \\
\text { tinta própria, } \\
\text { e paredes } \\
\text { que contem } \\
\text { presença de } \\
\text { mofo. }\end{array}$ & $\begin{array}{l}\text { Mutirão com } \\
\text { os alunos da } \\
\text { Universidade. }\end{array}$ & Não & Não & Não & Tinta & $\begin{array}{l}\text { Tinta / } \\
\text { Mutirão de } \\
\text { alunos }\end{array}$ & Tinta & $\begin{array}{l}\text { Conscienti- } \\
\text { zar os alunos } \\
\text { da importância } \\
\text { do enegreci- } \\
\text { mento das } \\
\text { janelas. }\end{array}$ \\
\hline $\begin{array}{l}\text { Fechamento } \\
\text { da abertura } \\
\text { que permite } \\
\text { a possível } \\
\text { entrada de } \\
\text { invasores. }\end{array}$ & $\begin{array}{l}\text { Diálogo com } \\
\text { a Prefeitura } \\
\text { para ceder } \\
\text { materiais e } \\
\text { mão de obra. }\end{array}$ & Sim & Sim & Sim & $\begin{array}{c}\text { Mão de } \\
\text { Obra / } \\
\text { Equipame } \\
\text { ntos }\end{array}$ & $\begin{array}{c}\text { Mão de } \\
\text { obra / } \\
\text { Equipament } \\
\text { os / } \\
\text { Materiais }\end{array}$ & Materiais & $\begin{array}{c}\text { Expor a } \\
\text { situação de } \\
\text { perigo que } \\
\text { pode ocorrer } \\
\text { com a invasão } \\
\text { da CAF }\end{array}$ \\
\hline
\end{tabular}


Resultados do planejamento estratégico situacional em uma central de abastecimento farmacêutico

\begin{tabular}{|c|c|c|c|c|c|c|c|c|}
\hline & $\begin{array}{l}\text { Diálogo com } \\
\text { a } \\
\text { Universidade } \\
\text { para ceder } \\
\text { materiais e } \\
\text { mão de obra. }\end{array}$ & Não & Não & Não & $\begin{array}{l}\text { Mão de } \\
\text { Obra / } \\
\text { Equipame } \\
\text { ntos }\end{array}$ & $\begin{array}{c}\text { Mão de } \\
\text { obra / } \\
\text { Equipament } \\
\text { os / } \\
\text { Materiais }\end{array}$ & Materiais & $\begin{array}{c}\text { Expor a } \\
\text { situação de } \\
\text { perigo que } \\
\text { pode ocorrer } \\
\text { com a invasão } \\
\text { da CAF }\end{array}$ \\
\hline $\begin{array}{c}\text { Troca das } \\
\text { geladeiras de } \\
\text { uso } \\
\text { doméstico, } \\
\text { para próprias } \\
\text { de } \\
\text { armazename } \\
\text { nto }\end{array}$ & $\begin{array}{l}\text { Orçamento e } \\
\text { apresentação } \\
\text { junto a } \\
\text { Prefeitura ou } \\
\text { Universidade. }\end{array}$ & Sim & Não & Não & $\begin{array}{l}\text { Recurso } \\
\text { financeiro }\end{array}$ & $\begin{array}{l}\text { Recurso } \\
\text { financeiro }\end{array}$ & $\begin{array}{l}\text { Recurso } \\
\text { financeiro }\end{array}$ & $\begin{array}{c}\text { Expor ao } \\
\text { Secretário de } \\
\text { Saúde e } \\
\text { Diretor do } \\
\text { Campus a } \\
\text { importância de } \\
\text { geladeiras } \\
\text { próprias ao } \\
\text { armazena- } \\
\text { mento. }\end{array}$ \\
\hline $\begin{array}{c}\text { Objetivo } \\
\text { específico } \\
02:\end{array}$ & \multicolumn{8}{|c|}{ Melhorar a qualidade de trabalho na Central de Abastecimento Farmacêutico } \\
\hline & \multirow[b]{2}{*}{ AÇÕES } & \multicolumn{3}{|c|}{$\begin{array}{c}\text { ANÁLISE DE } \\
\text { VIABILIDADE } \\
\text { (Poder) }\end{array}$} & \multicolumn{2}{|c|}{$\begin{array}{c}\text { ANÁLISE DE } \\
\text { FACTIBILIDADE }\end{array}$} & \multirow[t]{2}{*}{ Déficit } & \multirow{2}{*}{$\begin{array}{l}\text { ATIVIDAD } \\
\text { E } \\
\text { ESTRATÉ } \\
\text { GICA }\end{array}$} \\
\hline $\begin{array}{c}\text { OPERAÇO } \\
\text { ES }\end{array}$ & & $\begin{array}{c}\text { deci- } \\
\text { dir }\end{array}$ & $\begin{array}{l}\text { execu } \\
-\operatorname{tar}\end{array}$ & $\begin{array}{c}\text { man- } \\
\text { ter }\end{array}$ & $\begin{array}{l}\text { Recursos } \\
\text { existentes }\end{array}$ & $\begin{array}{c}\text { Recurso } \\
\text { necessário }\end{array}$ & & \\
\hline \multirow{2}{*}{$\begin{array}{l}\text { Retirar os } \\
\text { lixos } \\
\text { depositados } \\
\text { na área } \\
\text { externa, } \\
\text { próxima a } \\
\text { Copa. }\end{array}$} & $\begin{array}{l}\text { Conversar } \\
\text { com os } \\
\text { órgãos } \\
\text { públicos } \\
\text { localizados } \\
\text { próximo a } \\
\text { CAF para } \\
\text { retirada dos } \\
\text { objetos. }\end{array}$ & Sim & Sim & Não & Diálogo & Diálogo & Nenhum & $\begin{array}{l}\text { Conversar } \\
\text { com o } \\
\text { responsável } \\
\text { pelo órgão } \\
\text { ao lado }\end{array}$ \\
\hline & $\begin{array}{l}\text { Organizar } \\
\text { mutirão para } \\
\text { retirada dos } \\
\text { objetos. }\end{array}$ & Sim & Não & Não & Diálogo & Diálogo & Nenhum & $\begin{array}{l}\text { Conscienti- } \\
\text { zar os alunos } \\
\text { e sensibilizá- } \\
\text { los para os } \\
\text { problemas } \\
\text { que podem } \\
\text { causar este } \\
\text { acúmulo de } \\
\text { lixo. }\end{array}$ \\
\hline $\begin{array}{l}\text { Troca das } \\
\text { lixeiras de } \\
\text { papelão por } \\
\text { lixeiras de } \\
\text { plástico com } \\
\text { pedal. }\end{array}$ & $\begin{array}{l}\text { Compra de } \\
\text { lixeiras novas } \\
\text { com pedal }\end{array}$ & Sim & $\operatorname{Sim}$ & Sim & Nenhum & $\begin{array}{l}\text { Recurso } \\
\text { financeiro }\end{array}$ & $\begin{array}{l}\text { Recurso } \\
\text { financeiro }\end{array}$ & $\begin{array}{l}\text { Evidenciar a } \\
\text { todos a } \\
\text { importância } \\
\text { do uso das } \\
\text { lixeiras com } \\
\text { pedal. }\end{array}$ \\
\hline
\end{tabular}


Resultados do planejamento estratégico situacional em uma central de abastecimento farmacêutico

\begin{tabular}{|c|c|c|c|c|c|c|c|c|}
\hline $\begin{array}{l}\text { Contratação } \\
\text { de um } \\
\text { funcionário } \\
\text { para ficar } \\
\text { responsável } \\
\text { pela limpeza }\end{array}$ & $\begin{array}{c}\text { Buscar um } \\
\text { funcionário } \\
\text { capacitado e } \\
\text { disponível } \\
\text { para o } \\
\text { serviço e } \\
\text { dialogar com } \\
\text { a Prefeitura } \\
\text { para a } \\
\text { contratação } \\
\text { do mesmo. }\end{array}$ & Não & Não & Não & $\begin{array}{c}\text { Pesquisa } \\
\text { por } \\
\text { funcionário } \\
\text { capacitado } \\
\text { / Recurso } \\
\text { financeiro }\end{array}$ & $\begin{array}{c}\text { Pesquisa } \\
\text { por } \\
\text { funcionário } \\
\text { capacitado }\end{array}$ & $\begin{array}{l}\text { Recurso } \\
\text { financeiro }\end{array}$ & $\begin{array}{l}\text { Evidenciar } \\
\text { ao Secretário } \\
\text { de Saúde a } \\
\text { importância } \\
\text { de um } \\
\text { funcionário } \\
\text { próprio de } \\
\text { limpeza. }\end{array}$ \\
\hline $\begin{array}{l}\text { Evitar } \\
\text { acúmulo de } \\
\text { água parada }\end{array}$ & $\begin{array}{l}\text { Orientar os } \\
\text { funcionários } \\
\text { a ficarem } \\
\text { atentos a } \\
\text { possíveis } \\
\text { focos de } \\
\text { Dengue. }\end{array}$ & Sim & Sim & Sim & $\begin{array}{l}\text { Treinamen- } \\
\text { to / Busca } \\
\text { por focos }\end{array}$ & $\begin{array}{l}\text { Treinamen- } \\
\text { to / Busca } \\
\text { por focos }\end{array}$ & Nenhum & $\begin{array}{l}\text { Orientar os } \\
\text { funcionários } \\
\text { sobre o } \\
\text { problema de } \\
\text { água parada. }\end{array}$ \\
\hline
\end{tabular}

Por fim, chegamos ao último momento, o tático-operacional, considerado o momento da ação. Nesta etapa serão estipulados os valores a serem gastos, distribuídas as tarefas para cada participante e definidos os prazos a serem seguidos, conforme tabela 04.

Tabela 04 - Momento tático-operacional, etapa considerada da ação.

\begin{tabular}{|c|c|c|c|c|c|c|c|}
\hline \multirow{2}{*}{$\begin{array}{c}\text { Objetivos } \\
\text { Específic } \\
\text { os }\end{array}$} & \multirow[b]{2}{*}{$\begin{array}{l}\text { Opera- } \\
\text { ções }\end{array}$} & \multirow[b]{2}{*}{ Ações } & \multirow{2}{*}{$\begin{array}{l}\text { Recurso } \\
\text { financeiro }\end{array}$} & \multicolumn{2}{|c|}{$\begin{array}{l}\text { Responsabilidade e } \\
\text { Centralidade }\end{array}$} & \multirow[b]{2}{*}{ Prazo } & \multirow{2}{*}{$\begin{array}{c}\text { Indicador } \\
\text { de avaliação } \\
\text { (operação) }\end{array}$} \\
\hline & & & & $\begin{array}{c}\text { Ator } \\
\text { principal }\end{array}$ & $\begin{array}{c}\text { Outros } \\
\text { Parceiros }\end{array}$ & & \\
\hline \multirow[b]{3}{*}{$\begin{array}{l}\text { Melhorar a } \\
\text { infraestru- } \\
\text { tura da } \\
\text { Central de } \\
\text { Abasteci- } \\
\text { mento } \\
\text { Farmacêu- } \\
\text { tico }\end{array}$} & \multirow{2}{*}{$\begin{array}{c}\text { Troca } \\
\text { dos } \\
\text { pallets } \\
\text { de } \\
\text { madeira } \\
\text { por } \\
\text { pallets } \\
\text { de } \\
\text { plástico }\end{array}$} & $\begin{array}{c}\text { Buscar } \\
\text { investimento } \\
\text { com a } \\
\text { Prefeitura. }\end{array}$ & $\begin{array}{c}\mathrm{R} \$ 5000,00 \\
-\mathrm{R} \$ \\
8000,00\end{array}$ & $\begin{array}{l}\text { Secretaria de } \\
\text { Saúde }\end{array}$ & $\begin{array}{l}\text { Universidade } \\
\text { Federal de São } \\
\text { João Del Rei }\end{array}$ & $\begin{array}{l}\text { Junho } \\
\text { /2015 }\end{array}$ & $\begin{array}{c}\text { Consultar mês } \\
\text { a mês como } \\
\text { anda o } \\
\text { processo de } \\
\text { compra }\end{array}$ \\
\hline & & $\begin{array}{c}\text { Buscar } \\
\text { investimento } \\
\text { com a } \\
\text { Universidade } \\
\text {. }\end{array}$ & $\begin{array}{c}\mathrm{R} \$ 5000,00 \\
-\mathrm{R} \$ \\
8000,00\end{array}$ & $\begin{array}{l}\text { Universidade } \\
\text { Federal de } \\
\text { São João Del } \\
\text { Rei }\end{array}$ & $\begin{array}{l}\text { Secretaria de } \\
\text { Saúde }\end{array}$ & $\begin{array}{l}\text { Junho } \\
\text { /2015 }\end{array}$ & $\begin{array}{c}\text { Consultar mês } \\
\text { a mês como } \\
\text { anda o } \\
\text { processo de } \\
\text { compra e } \\
\text { doação. }\end{array}$ \\
\hline & $\begin{array}{c}\text { Compra } \\
\text { de } \\
\text { ventila- } \\
\text { dores } \\
\text { para as } \\
\text { salas } \\
\text { que não } \\
\text { possu- } \\
\text { em }\end{array}$ & $\begin{array}{c}\text { Obtenção de } \\
\text { orçamentos } \\
\text { de } \\
\text { ventiladores } \\
\text { e confecção } \\
\text { de ofício de } \\
\text { compra para } \\
\text { enviar á } \\
\text { prefeitura. }\end{array}$ & $\mathrm{R} \$ 1000,00$ & $\begin{array}{l}\text { Secretaria de } \\
\text { Saúde }\end{array}$ & --- & $\begin{array}{l}\text { Junho } \\
\text { /2015 }\end{array}$ & $\begin{array}{c}\text { Consultar mês } \\
\text { a mês como } \\
\text { anda o } \\
\text { processo de } \\
\text { compra }\end{array}$ \\
\hline
\end{tabular}


Resultados do planejamento estratégico situacional em uma central de abastecimento farmacêutico






\section{Resultados do planejamento estratégico situacional em uma central de abastecimento}

farmacêutico

\begin{tabular}{|c|c|c|c|c|c|c|c|}
\hline \multirow{5}{*}{$\begin{array}{l}\text { Melhorar a } \\
\text { qualidade } \\
\text { de trabalho } \\
\text { na Central } \\
\text { de } \\
\text { Abastecim } \\
\text { ento } \\
\text { Farmacêuti } \\
\text { co }\end{array}$} & & $\begin{array}{l}\text { CAF para } \\
\text { retirada dos } \\
\text { objetos. }\end{array}$ & & & & & \\
\hline & & $\begin{array}{l}\text { Organizar } \\
\text { mutirão para } \\
\text { retirada dos } \\
\text { objetos. }\end{array}$ & $\mathrm{R} \$ 0,00$ & $\begin{array}{c}\text { Aluno } \\
\text { extensionista } \\
\text { / } \\
\text { Universidade } \\
\text { Federal de } \\
\text { São João Del } \\
\text { Rei }\end{array}$ & $\begin{array}{l}\text { Secretaria de } \\
\text { Saúde }\end{array}$ & $\begin{array}{l}\text { Feve- } \\
\text { reiro/ } \\
2015\end{array}$ & $\begin{array}{c}\text { Incentivar os } \\
\text { alunos a } \\
\text { participarem e } \\
\text { explicitar a } \\
\text { importância } \\
\text { deste trabalho. }\end{array}$ \\
\hline & $\begin{array}{l}\text { Troca } \\
\text { das } \\
\text { lixeiras } \\
\text { de } \\
\text { papelão } \\
\text { por } \\
\text { lixeiras } \\
\text { de } \\
\text { plástico } \\
\text { com } \\
\text { pedal. }\end{array}$ & $\begin{array}{c}\text { Compra de } \\
\text { lixeiras novas } \\
\text { com pedal }\end{array}$ & $\mathrm{R} \$ 40,00$ & $\begin{array}{c}\text { Aluno } \\
\text { extensionista } \\
\text { / Central de } \\
\text { Abastecimen } \\
\text { to } \\
\text { Farmacêutico }\end{array}$ & $\begin{array}{l}\text { Secretaria de } \\
\text { Saúde / } \\
\text { Universidade } \\
\text { Federal de São } \\
\text { João Del Rei }\end{array}$ & $\begin{array}{l}\text { Feve- } \\
\text { reiro/ } \\
2015\end{array}$ & $\begin{array}{c}\text { Promover a } \\
\text { compra e troca } \\
\text { das lixeiras }\end{array}$ \\
\hline & $\begin{array}{l}\text { Contra- } \\
\text { tação } \\
\text { de um } \\
\text { funcio- } \\
\text { nário } \\
\text { para } \\
\text { ficar } \\
\text { respon- } \\
\text { sável } \\
\text { pela } \\
\text { limpeza }\end{array}$ & $\begin{array}{l}\text { Buscar um } \\
\text { funcionário } \\
\text { capacitado e } \\
\text { disponível } \\
\text { para o } \\
\text { serviço e } \\
\text { dialogar com } \\
\text { a Prefeitura } \\
\text { para a } \\
\text { contratação } \\
\text { do mesmo. }\end{array}$ & $\mathrm{R} \$ 880,00$ & $\begin{array}{l}\text { Secretaria de } \\
\text { Saúde }\end{array}$ & Nenhum & $\begin{array}{l}\text { Maio } \\
\text { /2015 }\end{array}$ & $\begin{array}{l}\text { Observar } \\
\text { como anda, } \\
\text { mês a mês, o } \\
\text { processo de } \\
\text { limpeza da } \\
\text { CAF e quanto } \\
\text { a contratação. }\end{array}$ \\
\hline & $\begin{array}{l}\text { Evitar } \\
\text { acúmu- } \\
\text { lo de } \\
\text { água } \\
\text { parada }\end{array}$ & $\begin{array}{l}\text { Orientar os } \\
\text { funcionários } \\
\text { a ficarem } \\
\text { atentos a } \\
\text { possíveis } \\
\text { focos de } \\
\text { Dengue. }\end{array}$ & $\mathrm{R} \$ 0,00$ & $\begin{array}{c}\text { Central de } \\
\text { Abastecimen } \\
\text { to } \\
\text { Farmacêutico }\end{array}$ & Nenhum & $\begin{array}{l}\text { Feve- } \\
\text { reiro/ } \\
2015\end{array}$ & $\begin{array}{c}\text { Promover } \\
\text { treinamento } \\
\text { aos } \\
\text { funcionários. } \\
\text { Dois meses } \\
\text { após, passar } \\
\text { mais um } \\
\text { treinamento. }\end{array}$ \\
\hline
\end{tabular}

Com o estudo formado e as tabelas de referência preenchidas, partiu-se a busca por ajuda através da Prefeitura Municipal e Universidade para tentar uma contrapartida na melhoria do espaço físico da CAF. Foram marcadas reuniões com o secretário de saúde de Divinópolis em duas oportunidades. O projeto arquitetônico já produzido, foi mais uma vez submetido à apreciação da Secretaria de Saúde, que alegou falta de verba para construção de um novo espaço e que iriam fazer alterações paliativas.

Adicionalmente reuniões com o diretor do Campus e os participantes do estudo foram realizadas. Ficou decidido que a Universidade, em contrapartida para melhoria do campo de estágio dos estudantes iria ceder pallets de plástico, adquiridos através de licitação, e doados para 


\section{Resultados do planejamento estratégico situacional em uma central de abastecimento}

farmacêutico

a CAF, além de, algumas propostas como mutirão de estudantes para pintar os edifícios seriam feitas junto com doação de tintas para tal.

Com a chegada dos pallets de plástico a doação foi feita, e neste meio tempo, foi feita mais uma visita em que se pôde perceber a troca das lixeiras de papelão, por adequadas de plástico com pedal. O lixo e depósitos de metal próximos à copa foram retirados e realocados em outros lugar. Também já havia sido feita licitação solicitando mais ventiladores e, além disso, nesta visita foi dada a informação de que a CAF seria transferida de local para um galpão alugado, pois a prefeitura estava solicitando o espaço, e que iriam investir em prateleiras adequadas e todo o suporte necessário que a CAF necessitava.

Posteriormente ocorreu liberação de verba, e com isso, a mudança do local da CAF para um galpão alugado pela prefeitura, onde foi feito um projeto arquitetônico em cima deste novo espaço para melhor utilização de sua área.

O novo galpão possuía uma estrutura física fechada e segura contra invasores, com presença de três entradas, uma na parte posterior para entrada dos caminhões e retirada dos medicamentos, uma lateral, e outra na parte anterior com interfone. No interior os medicamentos foram organizados em ordem alfabética para facilitar a identificação e separação, para correta distribuição. Os medicamentos controlados pela Portaria 344/98 foram separados e trancados dos demais medicamentos por uma grande divisória mais ao centro do galpão, e a chave, por sua vez, se encontrava com a farmacêutica responsável (BRASIL, 1998b).

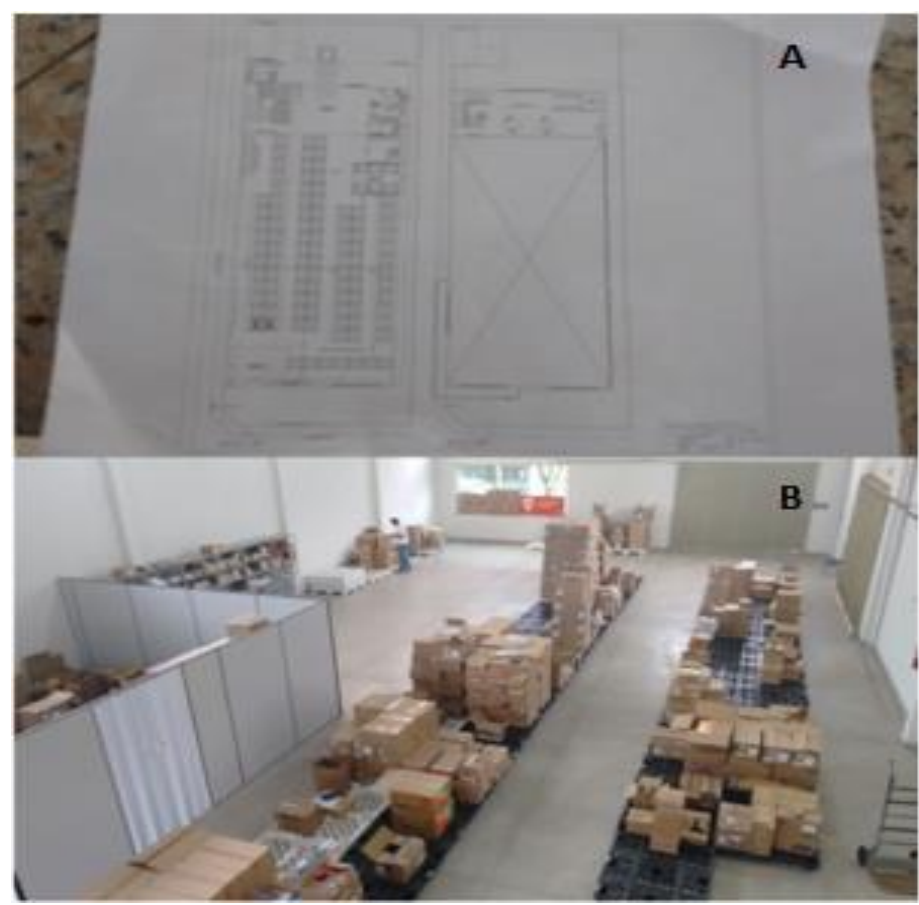

Figura 4: A- Projeto arquitetônico desenvolvido para estruturação da Central de Abastecimento Farmacêutico. BEstrutura da Central de Abastecimento Farmacêutico organizada no novo galpão. 
Resultados do planejamento estratégico situacional em uma central de abastecimento farmacêutico

O segundo andar ficou reservado para a parte administrativa, onde ficavam computadores utilizados para o controle de estoque, como entrada e saída dos medicamentos. Os documentos da CAF referentes a distribuição e licitações foram armazenados em prateleiras metálicas presentes também no segundo andar.

Havia também, um pequeno local na parte próxima a entrada posterior que estava sendo usada com o propósito de gerenciamento de resíduos de serviços de saúde dos tipos B, D e E, se adequando a RDC No 306/2004 (BRASIL, 2004).

O novo espaço ainda está sendo adaptado para o armazenamento dos medicamentos, ocorrendo ainda algumas não conformidades, como presença de geladeiras de uso doméstico que, futuramente, a gestão municipal pretende trocá-las por geladeiras próprias para armazenamento.

\section{CONSIDERAÇÕES FINAIS}

O armazenamento do medicamentos feito da forma correta, possibilita a efetividade do tratamento do paciente, e a CAF, com uma estrutura defasada em relação ao que realmente deveria ser, poderia comprometer a efetividade deste. Para o estagiário do curso de farmácia, uma gritante dicotomia entre realidade e pratica apresentava-se. Por meio destes problemas teve início a busca de soluções, e em um trabalho em conjunto com Universidade e Prefeitura, foram conquistados resultados satisfatórios, em que foram observados um grande avanço em relação a estrutura, disposição e forma de trabalhar na CAF.

Agradecimentos: SEMUSA e PROEX UFSJ

\section{REFERÊNCIAS BIBLIOGRÁFICAS}

FUREGATO, Antonia Regina Ferreira. Políticas de saúde mental do Brasil. Rev. esc. enferm. USP. June 2009; v.43 No.2.

CORRER C.J., OTUKI M.F., SOLER O. Assistência Farmacêutica integrada ao processo de cuidado em saúde: gestão clínica do medicamento. Rev Pan-Amaz Saude. Set. 2011; v.2 n.3.

OLIVEIRA L.C.F de, ASSIS M.M.A., BARBONI A.R. Assistência Farmacêutica no Sistema Único de Saúde: da Política Nacional de Medicamentos à Atenção Básica à Saúde. Ciênc. saúde coletiva. Nov. 2010; vol.15 suppl.3. 
Resultados do planejamento estratégico situacional em uma central de abastecimento farmacêutico

Ministério da Saúde (BR). Secretaria de Ciências, Tecnologia e Insumos Estratégicos. Departamento de Assistência Farmacêutica. Assistência farmacêutica na atenção básica: instruções técnicas para sua organização. Brasília, 2006.

MATUS, C. Política, planejamento e governo. Brasília, DF: Instituto de Economia Aplicada, 1993.

Leite, S. N., et al. Gestão da Assistência Farmacêutica. Assistência Farmacêutica no Brasil: Política, Gestão e Clínica. Florianópolis: EdUFSC, 2016.

BRASIL. ANVISA. Agência Nacional de Vigilância Sanitária. Resolução - RDC nº 50, de 21 de fevereiro de 2002- Dispõe sobre o Regulamento Técnico para planejamento, programação, elaboração e avaliação de projetos físicos de estabelecimentos assistenciais de saúde. Disponível em: <http://www.anvisa.gov.br/anvisalegis/resol/2002/50 02rdc.pdf >. Acesso em 26 de agosto de 2016.

Ministério da Saúde (BR). Portaria $\mathrm{n}^{\circ}$ 802, de 08 de outubro de 1998a. Disponível em: $<$ http://bvsms.saude.gov.br/bvs/saudelegis/anvisa/1998/prt0802 0810 1998.html>. Acesso em 26 de agosto de 2016.

MARIN, N. et al (Org.). Assistência farmacêutica para gerentes municipais. Rio de Janeiro: Opas, 2003.

BRASIL. ANVISA. Agência Nacional de Vigilância Sanitária. Resolução - RDC n. ${ }^{\circ}$ 306, de 07 de dezembro de 2004 -Dispõe sobre o Regulamento Técnico para o gerenciamento de resíduos de serviços de saúde. Disponível em: < http://www.anvisa.gov.br/servicosaude/manuais/manual gerenciamento residuos.pdf $>$. Acesso em 26 de agosto de 2016.

BRASIL. ANVISA. Agência Nacional de Vigilância Sanitária. Portaria n. ${ }^{\circ}$ 344, de 12 de maio de 1998b. Aprova o Regulamento Técnico sobre substâncias e medicamentos sujeitos a controle especial. Disponível em: < http://www.anvisa.gov.br/hotsite/talidomida/legis/Portaria 344 98.pdf $>$. Acesso em 26 de agosto de 2016. 